\title{
Anti-herpetic activity of a combination of L-asparaginase and cytosine arabinoside used in vitro
}

\author{
ROGER CAPPEL
}

\section{LISE THIRY}

\author{
JEAN KLASTERSKY
}

Service de Médecine et Laboratoire d'Investigation Clinique (Section des Maladies Infectieuses), Institut Jules Bordet, Centre des Tumeurs de l'Université Libre de Bruxelles, and Department of Virology, Institut Pasteur du Brabant, Brussels, Belgium

THE discovery of the antiviral properties of 5-iodo2'-deoxyuridine (IDU), arabinoside cytosine (ARAC), L-asparaginase and of some derivatives of rifampicin holds out new perspectives for the treatment of severe viral diseases, such as herpetic encephalitis and opportunistic viral illnesses in the immuno-depressed host. For these infections a valuable chemotherapeutic regimen still remains to be discovered. Therefore, we have invesigated in vitro the antiviral activity of IDU, Ara-C and Lasparaginase and the efficacy of their combinations against a strain of herpes simplex virus. To keep this note brief, we will report here only a few preliminary results obtained in our laboratory with the combinations Ara-C/L-asparaginase and IDU/L-asparaginase.

The antiviral activity of these two associations of antiviral drugs was tested using two methods: firstly, the technique using the inhibition of the formation of viral plaques; and secondly a micromethod based on a technique used by others to investigate mechanisms of cellular immunity (Takasugi \& Klein, 1970). Each well of a Terasaki's plaque, containing 500 cells, was inoculated with $10 \mu$ l of medium 199 with $1000 \mathrm{TCD}_{50}$ of the test virus. After $2 \mathrm{hr}$, the

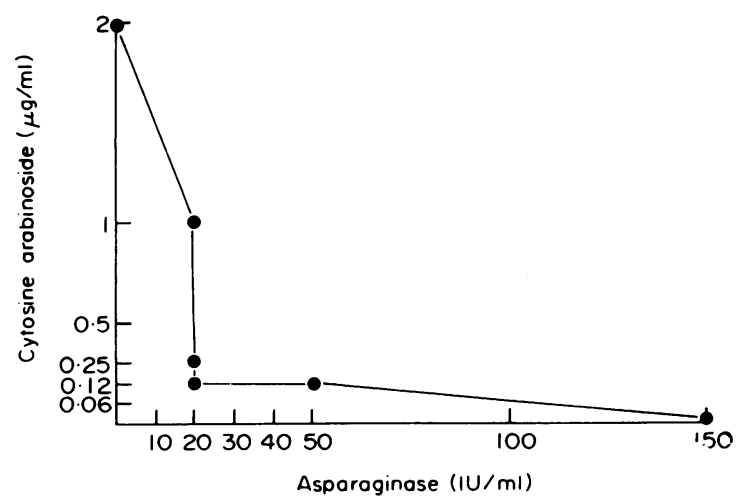

FIg. 1. Synergistic effect of the Ara-C/L-asparaginase combination is suggested by the downwards bowed isobol obtained with these drugs. Protection afforded by L-asparaginase plus arabinoside cytosine against the cytopathic effect of herpes simplex type I on HEP cells using the microtest culture plates of Terasaki. Each point gives the combined doses which protected $100 \%$ of the cells against viral cytopathic effect. wells were emptied and $10 \mu \mathrm{l}$ of medium 199 containing the combinations of drugs to be tested were added to the infected cells. The result was evaluated after $48 \mathrm{hr}$ as a $100 \%$ inhibition of the cytopathogenic effects (CPE) when no such effects could be found. For each concentration of the drugs used here, whether alone or in combination, 250 wells were examined. The results obtained by the two methods were concordant. As shown in Fig. 1, the combination Ara-C/L-asparaginase was found to be synergistic on the test strain. On the other hand, the combination IDU/L-asparaginase was only additive.

The synergistic effect of Ara-C and L-asparaginase when used in combination against herpes simplex virus was tested here on different cells (rabbit kidney, chicken fibroblasts and $\mathrm{HEP}_{2}$ ). It should be pointed out, however, that the concentration of $\mathrm{L}-\mathrm{O}$ asparaginase required to produce $100 \%$ inhibition of CPE varied to a certain extent depending on the type of cell used. This might be explained by variable content in L-asparaginase of the cells used in these experiments.

The synergistic effect found in these studies might prove to be of clinical interest since it might allow a reduction in the toxicity caused by both Ara-C (on bone marrow) and L-asparaginase (on the liver) and still obtain a significant antiviral effect.

Therefore, these studies suggest that a clinical controlled trial might be undertaken in patients presenting serious herpetic diseases such as encephalitis. The respective efficacy of Ara-C alone, which is already used (Juel-Jensen, 1970), and of the combination Ara-C/L-asparaginase should be evaluated. Therapy with L-asparaginase alone cannot be safely recommended, however, since in vitro very high levels of that drug, that cannot be obtained in body fluids, were not capable of $100 \%$ inhibition of CPE.

\section{Acknowledgments}

The technical assistance of Mrs G. Drevillon and the editorial assistance of Miss $R$. Tebbutt are gratefully acknowledged.

\section{References}

JUEL-JenSEN, B. E. (1970) Severe generalized primary herpes treated with cytarabine. British Medical Journal, 2, 154.

TAKasugi, M. \& KLein, E. (1970) A microassay for cellmediated immunity. Transplantation, 9, 219. 